\title{
Cu(II)-Imprinted Nanoparticles for Real Time Detection of Cu(II) lons
}

\author{
Müge Andaç', Nihan Aydoğan¹, Monireh Bakhshpour ${ }^{2}$, Adil Denizli ${ }^{2}$ \\ ${ }^{1}$ Department of Environmental Engineering, Hacettepe University \\ 06800 Ankara, Turkey \\ andac@ hacettepe.edu.tr; aydogannihan@hotmail.com \\ ${ }^{2}$ Department of Chemistry, Hacettepe University \\ 06800 Ankara, Turkey \\ b.monir@hacettepe.edu.tr; denizli@hacettepe.edu.tr
}

\section{Extended Abstract}

Although, $\mathrm{Cu}$ (II) plays an essential role in physiological processes in certain amounts, $\mathrm{Cu}$ (II) can react with molecular oxygen to generate reactive oxygen species (ROS), suggesting their potential damage to biomolecules at elevated concentrations. In this regard, the residual level of $\mathrm{Cu}$ (II) in drinking water is restricted. The United States Environment Protection Agency (USEPA) sets a maximum contaminant level (MCL) of $\mathrm{Cu}$ (II) at $1.3 \mathrm{ppm}(20 \mathrm{mM})$ in drinking water. Therefore, it is important to develop sensitive and selective analytical methods for the detection of $\mathrm{Cu}$ (II) ions [1]. Ion imprinting technology is one of the most promising tools in separation and purification systems because of selectivity, good stability, simplicity and low cost. It thephas been mainly used for selective removal and pre-concentration and sensing fields [2-4]. In ion sensing, various ion imprinted polymers (IIPs) based sensors have been developed for detection of toxic metal ions. Among these, quartz crystal microbalance (QCM), high-resolution mass sensing technique, measures changes in mass on an oscillating quartz crystal surface in real time. The mass sensing technique is advantageous to obtain label-free, selective, simple, and stable detection. QCM technique have already been used in the detection of environmental contaminants [5].

In this research study, for the first time, $\mathrm{Cu}$ (II) ions were detected quantitatively in real time with high sensitivity and selectivity without any laboratory conditions and expensive instruments. The study targets to prepare a gravimetric nanosensor for the analysis of $\mathrm{Cu}$ (II) ions by combining the excellent selectivity properties of ion imprinted polymers (IIPs) and nanotechnology. Thus, poly(hydroxyethyl-methacrylate) (pHEMA) based Cu(II) ion imprinted nanoparticles $(\mathrm{Cu}-\mathrm{IIN})$ were prepared in a size range of $60 \mathrm{~nm}$. These $\mathrm{Cu}$-IIN were characterized by several methods, such as scanning electron microscopy (SEM), zeta size distribution analysis and FTIR spectroscopy. Cu-IIN were then adapted to QCM nanosensor for the real time detection of $\mathrm{Cu}(\mathrm{II})$ ions in aqueous solutions. Several parameters, such as $\mathrm{pH}$, initial ion concentration and selectivity were investigated to obtain the optimum conditions of QCM nanosensor efficiency. The results showed that QCM nanosensor has high selectivity and sensitivity for $\mathrm{Cu}(\mathrm{II})$ ions even in a wide range of $4.06 \mathrm{nM}-$ $4.06 \mathrm{pM}$. The specificity of the QCM nanosensor was shown by competitive adsorption of $\mathrm{Co}$ (II), $\mathrm{Ni}$ (II), $\mathrm{Zn}$ (II) and Fe(II) ions. Finally, the QCM nanosensor is used for five adsorption and desorption regeneration cycle and it gives reproducible response. The results are promising for developing a new strategy in the detection of environmental contaminants by combining ion imprinted polymers (IIPs) and nanotechnology.

\section{References}

[1] H. Chen, J. Zhang, X. Liu, Y. Gao, Z. Ye, G. Li, "Colorimetric copper(II) ion sensor based on the conformational change of peptide immobilized onto the surface of gold nanoparticles," Anal. Methods, vol. 6, pp. 2580-2585, 2014.

[2] M. Andaç, R. Say, A. Denizli, "Molecular recognition based cadmium removal from human plasma," $J$. Chromatogr. B-Analyt. Technol. Biomed. Life Sci., pp. 119-126, 2004.

[3] M. Andaç, E. Özyapı, S. Senel, R. Say, A. Denizli, "Ion-selective imprinted beads for aluminum removal from aqueous solutions," Ind. Eng. Chem. Res., pp. 1780-1786, 2006.

[4] C. Branger, W. Meouche, A. Margaillan, "Recent Advances on Ion-Imprinted Polymers," React. Funct. Polym., vol. 73, no. 6, pp. 859-875, 2013. 
[5] U. Latif, A. Mujahid, A. Afzal, "Dual and tetraelectrode QCMs using imprinted polymers as receptors for ions and neutral analytes," Anal. Bioanal. Chem., vol. 400, pp. 2507-2515, 2011. 